\title{
Cultivation of Complex Engineering Problem Analysis Ability of Electrical Engineering Undergraduates Based on Scientific Research Platform
}

\author{
Quan Chen ${ }^{1, *}$, Jun $\mathrm{Tao}^{1}$, Xijun Yang ${ }^{2}$, Guoli $\mathrm{Li}^{1}$ \\ ${ }^{1}$ School of Electrical Engineering and Automation, Anhui University, Hefei 230601, China \\ ${ }^{2}$ Department of Electrical Engineering, Shanghai Jiao Tong University, Shanghai 200240, China \\ *Corresponding author. Email: chquan@126.com
}

\begin{abstract}
Improving the ability of electrical engineering undergraduates to solve complex engineering problems is an eternal topic of "student-centered" talent training. Based on the HIL (hardware-in-loop) real-time simulation research platform, this paper designs four comprehensive experiments covering electrical engineering, power electronics, power system analysis and other courses, and gives a brief theoretical analysis and experimental verification for each experiment. According to the survey of "learning evaluation", Graduate Survey and the analysis of the theme demand of graduation thesis, the teaching of Electrical Engineering Undergraduates Based on the semi physical real-time simulation platform can improve the students' ability to analyse complex problems, and also provide a way for the scientific research platform to assist undergraduate teaching.
\end{abstract}

Keywords: HIL real-time simulation, Electrical engineering, Complex engineering problems, Ability development.

\section{INTRODUCTION}

Complexity is the essential feature of modern engineering problems. There are 8 graduation requirements mentioned in the engineering education accreditation standard revised in November 2017, which involve "complex engineering problems"[1]. Therefore, how to effectively solve "complex engineering problems" in student-centered teaching is an eternal topic. The supplementary standard for electronic information and electrical engineering specialty stipulates the curriculum of electrical specialty. Most of the courses of electrical engineering, as everyone knows, are closely integrate theory with practice. It is a way to strengthen the cultivation of undergraduates' ability to solve "complex engineering problems" in experimental courses.

Experimental education provides valuable practical experience for the connection between theory and the real world[2]. Over the past decades, it has been increasingly recognized that it is necessary to bring comprehensive experiment into electrical system, especially distribution network, which is closely related to the three directions of electrical engineering, such as motor, power electronics and power system[3]. Therefore, for the cultivation of electrical engineering undergraduates, it is necessary to carry out appropriate laboratory exercises at the distribution network level. Some institutions have realized this demand and made contributions to the experimental education in this field [4].

Due to space and cost limitation of hardware (including generator, transformer, line, load, OLTC, inverter) in the laboratory, especially the comprehensive experiment of complex electrical system usually uses simulation software or less special hardware [5]. Although this method opens up a new way for education, the physical phenomenon and the power system hardware are not able to be understood by students. HIL Simulation combines simulation with hardware testing, which not only provides students with hardware experience, but also makes full use of the advantages of digital simulation [6].

In this paper, it is the first time HIL simulation research platform is applied to the practical education of electrical system course, and the feasibility of training students to solve "complex engineering problems" is 
proved. The second part summarizes the electrical system comprehensive experimental platform based on RT-lab. The third part describes four experimental exercises. The fourth part reports the students' feedback, and the fifth part is conclusion.

\section{COMPREHENSIVE EXPERIMENTAL PLATFORM OF ELECTRICAL SYSTEM IN AHU}

Opal-RT is a real-time digital simulator based on PC and FPGA technology [4]. It is used to control prototype simulation and HIL simulation. Opal-RT system can be used for the design, verification and optimization of complex control system. As shown in Figure 1, the semi-physical simulation platform of AHU for integrated electrical system experiment includes OpalRT op5707-8v simulator, host, auxiliary power supply, etc. The software supported by the platform includes MATLAB, Artemis, RT-lab, eFPGA SIM, RT events, RT-XSG and Siemens DIGSI manager. The parameters of this platform are shown in Table 1 .

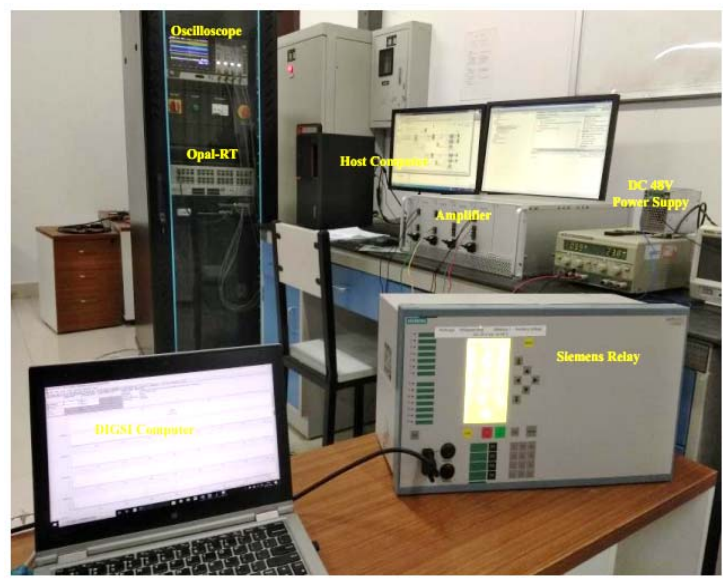

Figure 1 HIL simulation platform of AHU.

Table 1. Components of HIL simulation platform based on Opal-RT

\begin{tabular}{|c|l|l|}
\hline $\begin{array}{c}\text { hardwar } \\
\text { e }\end{array}$ & host & $\begin{array}{l}\text { Intel i7, 4 cores, CPU 3.0GHz, } \\
\text { 16GB RAM, 1TB HDD, Gigabit } \\
\text { LAN }\end{array}$ \\
\cline { 2 - 3 } & simulator & $\begin{array}{l}\text { OP5707 RCP/HIL FPGA-based } \\
\text { Real-Time Simulator. Intel 8 } \\
\text { cores, 3.2 GHz CPU, 8G RAM, } \\
\text { Redhat Linux Real time operating } \\
\text { system and compiler }\end{array}$ \\
\cline { 2 - 3 } & $\begin{array}{l}\text { Analogue } \\
\text { and } \\
\text { ital module }\end{array}$ & 32 channels, 16bits, +16V, 5mA \\
\hline software & $\begin{array}{l}\text { Electrical } \\
\text { simulatio } \\
\mathrm{n} \\
\text { software }\end{array}$ & $\begin{array}{l}\text { ARTEMIS, Tardive and RT- } \\
\text { Events, RT-LAB eFPGA SIM, } \\
\text { RT-XSG, Matlab }\end{array}$ \\
\hline
\end{tabular}

\section{COMPREHENSIVE EXPERIMENTS OF ELECTRICAL SYSTEM}

\subsection{Introduction of Experimental Objects}

As shown in Figure 2, the experimental objects include step-down transformer, rectifier transformer, three-phase 4-quadrant converter and reactive power compensation (RPC) composed of TCR and LC hybrid filter. The subjects of the experiment are related to the four courses of power electronics, electrical machinery, power system, power quality analysis and control (professional elective course) of electrical engineering. The parameters of the experimental objects are shown in Table 2, and the simulation system framework based on Opal -RT simulation platform is shown in Figure 3.

\subsection{Experimental Design}

\subsubsection{Experiment on Inrush Current}

Characteristics of Three Phase Transformer

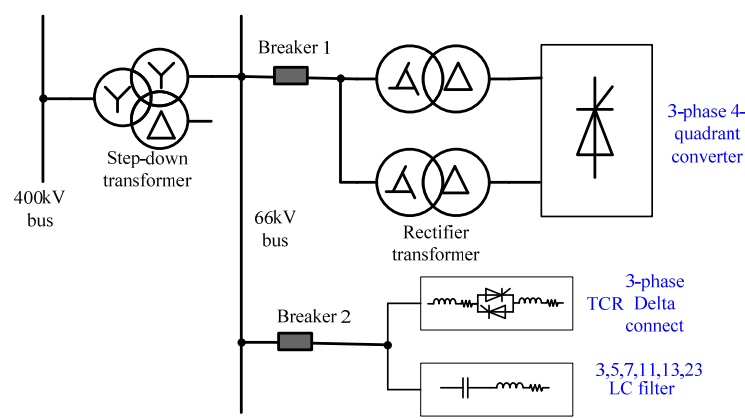

Figure 2 The HIL simulation experimental objects.

Table 2. Parameters of experimental objects

\begin{tabular}{|c|c|}
\hline Item & Parameters \\
\hline TCR & $\mathrm{L}=2 \times 0.056087 \mathrm{H} ; \mathrm{R}=2 \times 0.04217 \Omega$ \\
\hline 3rd Filter & $\begin{array}{l}\mathrm{R}=0.1722 \Omega ; \mathrm{L}=0.06893 \mathrm{H} ; \\
\mathrm{C}=16.7144 \mu \mathrm{F} ; \text { High pass } \\
\text { Resistance: } 1000 \Omega\end{array}$ \\
\hline 5th Filter & $\begin{array}{l}\mathrm{R}=0.018 \Omega ; \mathrm{L}=0.008255 \mathrm{H} ; \\
\mathrm{C}=50.1433 \mu \mathrm{F}\end{array}$ \\
\hline 7th Filter & $\begin{array}{l}\mathrm{R}=0.02447 \Omega ; \mathrm{L}=0.006326 \mathrm{H} ; \\
\mathrm{C}=33.4289 \mu \mathrm{F}\end{array}$ \\
\hline 11th Filter & $\begin{array}{l}\mathrm{R}=0.01758 \Omega ; \mathrm{L}=0.002552 \mathrm{H} ; \\
\mathrm{C}=33.4289 \mu \mathrm{F}\end{array}$ \\
\hline 13th Filter & $\begin{array}{l}\mathrm{R}=0.02074 \Omega ; \mathrm{L}=0.002333 \mathrm{H} ; \\
\mathrm{C}=26.1983 \mu \mathrm{F}\end{array}$ \\
\hline 23th Filter & $\begin{array}{l}\mathrm{R}=0.03088 \Omega ; \mathrm{L}=0.001119 \mathrm{H} ; \\
\mathrm{C}=17.4656 \mu \mathrm{F} ; \text { High pass } \\
\text { Resistance: } 17.5 \Omega\end{array}$ \\
\hline $\begin{array}{l}\text { Step-down } \\
\text { transformer }\end{array}$ & $\begin{array}{l}\mathrm{Y}_{\mathrm{n}}-\mathrm{Y}_{\mathrm{n}}-\mathrm{Delta}(\mathrm{D} 11), 400 / 66 \mathrm{kV} \\
\text { 300MVA }\end{array}$ \\
\hline $\begin{array}{l}\text { Rectifier } \\
\text { transformer }\end{array}$ & $\begin{array}{l}\text { Grid side: Extended triangle, phase } \\
\text { shift } \pm 15^{\circ} ; \text { Converter side: Delta; } \\
66 / 1.05 \mathrm{kV} ; 41 \mathrm{MVA}\end{array}$ \\
\hline
\end{tabular}




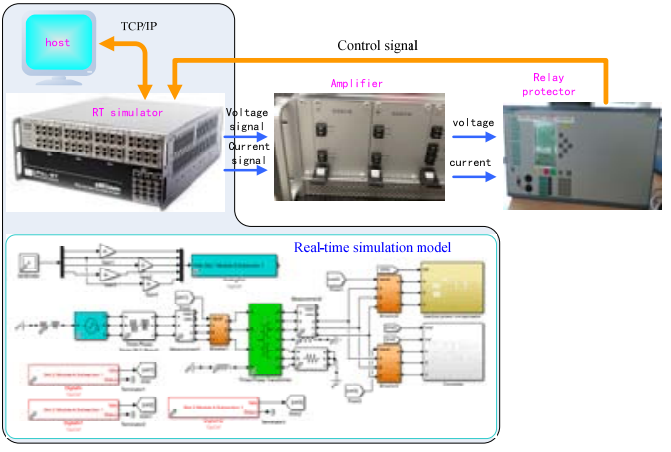

Figure 3 Simulation system framework based on Opal RT simulation platform.

Three-phase transformer and its related theory is an important part of electrical machinery, and also an important part of power system [7]. Its normal operation has an important impact on power supply reliability. Understanding the inrush current characteristics of transformer is helpful to the parameter setting of microcomputer relay protection device, and it is also helpful for students to master the nonlinear relationship between current and flux in the process of transformer closing and its influencing factors [8]. The three-phase three-winding step-down transformer, shown in Fig.2, is connected by Yn-Yn-D11. According to the circuit connection and based on the model in Figure 3, the noload closing process of the three-phase $\mathrm{Yn}-\mathrm{Yn}$ threephase transformer is analysed.

For three-phase transformer, three-phase voltage as $u_{x}=\sqrt{2} U_{2} \sin (\omega t+\alpha-2 k \pi / 3) \quad(\quad x=a, b, c$, corresponding $k=0,1,2$ ), then according to $\mathrm{KVL}$ theorem, the relationship between phase-phase voltage and current of three-phase transformer are given as (1)(3).

$$
\begin{aligned}
u_{a b}= & R\left[i_{a}(t)-i_{b}(t)\right]+L \frac{d\left[i_{a}(t)-i_{b}(t)\right]}{d t} \\
& +N\left[\frac{d \phi_{a}(t)}{d t}-\frac{d \phi_{b}(t)}{d t}\right] \\
u_{b c}= & R\left[i_{b}(t)-i_{c}(t)\right]+L \frac{d\left[i_{b}(t)-i_{c}(t)\right]}{d t} \\
& +N\left[\frac{d \phi_{b}(t)}{d t}-\frac{d \phi_{c}(t)}{d t}\right] \\
i_{a}(t) & +i_{b}(t)+i_{c}(t)=0
\end{aligned}
$$

In (1) and (2), considering $\phi(t)=A B(t)$ and $H(t)=N i(t) / P$, expression (4) can be get.

$N \frac{d \phi(t)}{d t}=\frac{N^{2} A}{P} \frac{d B(t)}{d H(t)} \frac{d i(t)}{d t}$

It can be seen from above expression that the inrush current of transformer closing contains a large number of aperiodic components, and the maximum current will reach 6-8 times of the rated current (related to $\alpha$ ). As the three-phase transformer connected to the three-phase voltage, the phase difference is $1 / 3$ period. Therefore, it is impossible to eliminate the inrush current of the transformer at any closing time point. There is a serious current bias in a certain phase, which contains a large number of even harmonics.

Figure 4 shows the phase current waveform of threephase transformer when $\alpha=0^{\circ}$. It can be seen that the current waveform is discontinuous. Generally, the higher the saturation degree of the core is, the greater the inrush current is and the greater the discontinuity angle is. According to the characteristics of inrush current, appropriate measures can be taken to avoid the differential protection of inrush current.

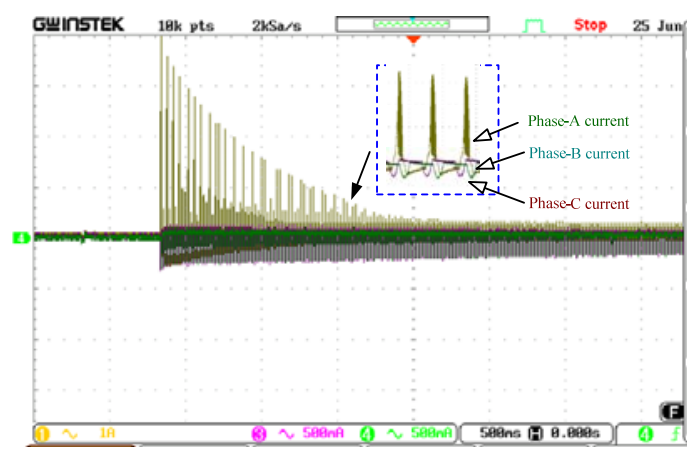

Figure 4 Inrush current of no-load closing of threephase transformer.

\subsubsection{Electromagnetic Transient Experiment of Power System}

The experiment of electromagnetic transient process in power system is realized by the breaking of mechanical switch, such as breaker module or power electronic equipment [9]. In this experiment, the threephase grounding short circuit fault occurred in no-load operation of transformer is studied. This fault case is located in the secondary side of $400 \mathrm{kV} / 66 \mathrm{kV}$ transformer. The relay protector is used in the experiment. When it exceeds the set value, the relay protector sends the circuit breaker off signal for protection.

If the line resistance, line reactance and transformer reactance are $R_{L}, X_{L}$ and $X_{T}$, respectively. The amplitude of periodic component of short circuit current $I_{p s}$ at low voltage side of transformer can be calculated:

$I_{p s}=\frac{\sqrt{2} U_{1}}{\sqrt{3} \sqrt{R_{L}^{2}+\left(X_{L}+X_{T}\right)^{2}}} \times k_{n}$

In (5), $U_{1}$ is the RMS value of the primary side voltage of the transformer, and $k_{n}$ is the ratio of the primary side voltage to the secondary side voltage.

The impulse current $i_{i m}$ is 


$$
i_{i m}=\left[1+e^{\frac{-R_{L} /(2 f)}{\left(X_{L}+X_{T}\right) /(2 \pi f)}}\right] I_{p s}
$$

Where $f$ is the frequency of $\mathrm{AC}$ power grid.

After the fault occurs, the current waveforms of phase $\mathrm{A}$ and phase $\mathrm{C}$ and the tripping signal of primary circuit breaker are shown in Figure 5.

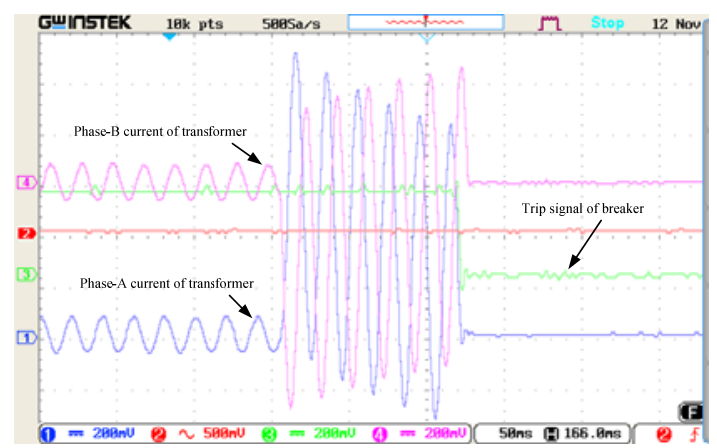

Figure 5 Three phase short circuit current to ground and trip control signal of transformer.

\subsubsection{Four-quadrant Operation of Converter}

Considering large current and four-quadrant operations of load, two sets of positive-group and negative-group parallel operation are adopted, as shown in Figure 6. In order to obtain the load current waveform and amplitude as shown in Figure 7, it can be seen that the working states of the four bridge arms are different at different stages of the load current [10]. It will go through five stages: parallel operation of CU2 and CU4, separate operation of CU4, circulation operation of CU1 and CU4, separate operation of CU1 and parallel operation of CU1 and CU3. For example, the circulation operation is a relatively complex control process, and the control strategies are as follows:

$$
\begin{aligned}
& \alpha_{1 c i r}=\cos ^{-1}\left(\frac{U_{r e f}+\Delta u_{1}+\Delta u_{c i r}}{1.35 V_{L L}}\right) \\
& \Delta u_{1}=I_{d 1} \cdot\left(R_{p}+2 R_{a r m}+2 \pi f L_{p}\right)+2 V_{t h} \\
& \alpha_{4 c i r}=\cos ^{-1}\left(\frac{\Delta u_{4}+\Delta u_{c i r}-U_{r e f}}{1.35 V_{L L}}\right) \\
& \Delta u_{4}=I_{d 4} \cdot\left(R_{p}+2 R_{a r m}+2 \pi f L_{p}\right)+2 V_{t h} \\
& \Delta u_{c i r}=\left(I_{c}-I_{c i r}\right) \cdot\left(K_{p}+\frac{K_{I}}{s}\right) \\
& I_{c i r}=\left|I_{d 1}+I_{d 4}-I_{d}\right| / 2
\end{aligned}
$$

In the above expressions, $L_{p}$ and $R_{p}$ are the inductance and resistance of DC reactor. $I_{d}, I_{d 1}, I_{d 4}$ and $I_{c i r}$ are load current, CU1 arm current, CU4 arm current and circulating current; $V_{L L}$ and $f$ are the RMS value and frequency of phase-phase voltage, respectively. $U_{\text {ref }}$ is the command signal. $R_{\text {arm }}$ and $V_{t h}$ are the equivalent resistance of bridge arm and the forward voltage drop of thyristor. $\alpha_{1 \text { cir }}$ and $\alpha_{4 \text { cir }}$ are the control angles of CU1 and CU4 in circulation stage.

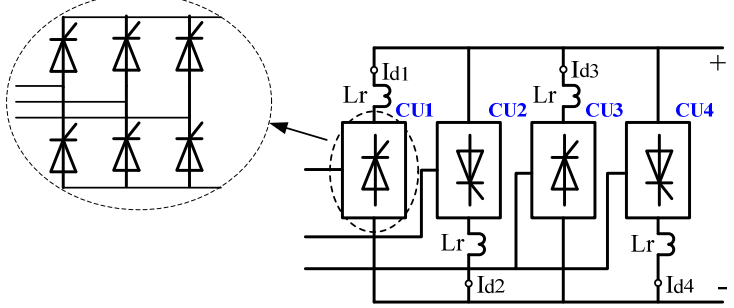

Figure 6 Four-quadrant converter.

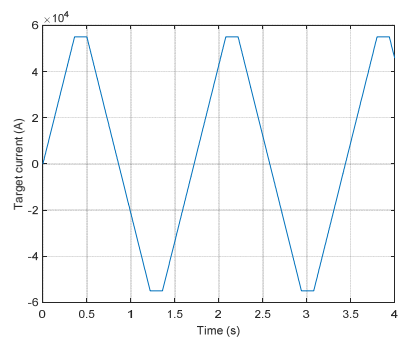

Figure 7 Expected current waveform.

The results are shown in the Figure 8. From the results, it can be seen that it meets the expectation through the control.

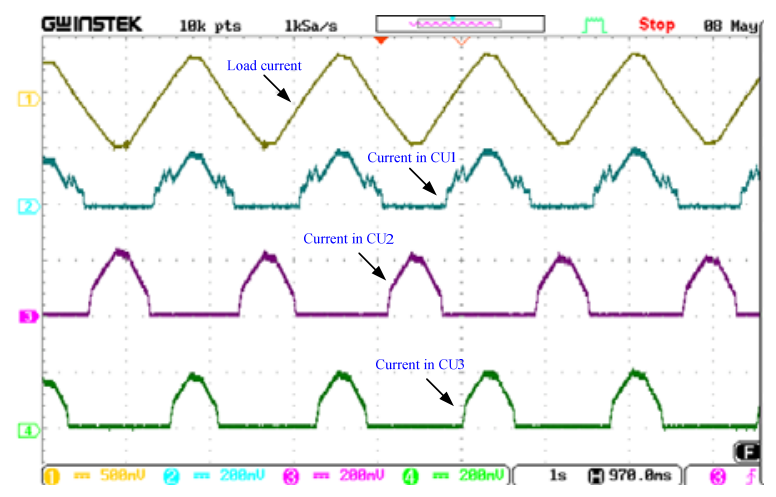

Figure 8 Based on Opal-RT experimental results (topdown: load current, CU1 current, CU2 current, CU3 current).

\subsubsection{Reactive Power Compensation in Distribution Network System}

Power electronics, electrical engineering and power system analysis are the main professional courses of electrical engineering. Power quality analysis and control of distribution network system involves the comprehensive application of these three courses, among which reactive power compensation is the most representative field [11]. Especially in the case of pulsepower or step-power change, for system voltage stability and harmonic compensation, RPC $+\mathrm{HF}$ (reactive power compensation + harmonic filtering) is usually installed nearby to suppress the reactive power 
and harmonic problems caused by power converter, which is an economical and flexible scheme in industry.

In this example, the RPC $+\mathrm{HF}$ system consists of a TCR rated at 250 Mvar and six harmonic filters tuned to the $3 \mathrm{rd}, 5 \mathrm{th}, 7 \mathrm{th}, 11 \mathrm{th}, 13 \mathrm{th}$ and $23 \mathrm{rd}$ harmonics of 50 $\mathrm{Hz}$ connected to the $66 \mathrm{kV}$ bus. The total fundamental reactive power generated by the filter is $250 \mathrm{Mvar}$. The experimental waveforms based on hardware in the loop simulation and the simulation waveforms based on MATLAB are shown in Figure 9. In Figure 9(a), using $\mathrm{RPC}+\mathrm{HF}$ mode, when the active power changes, the reactive power on the $66 \mathrm{kV}$ bus has a small fluctuation and then quickly returns to zero, and the bus voltage is stable. In Figure 9(b) and9 (c), simulation results show the converter reactive power, bus reactive power, compensation circuit reactive power and TCR thyristor control angle are controlled by $116^{\circ}$ to $112^{\circ}$.

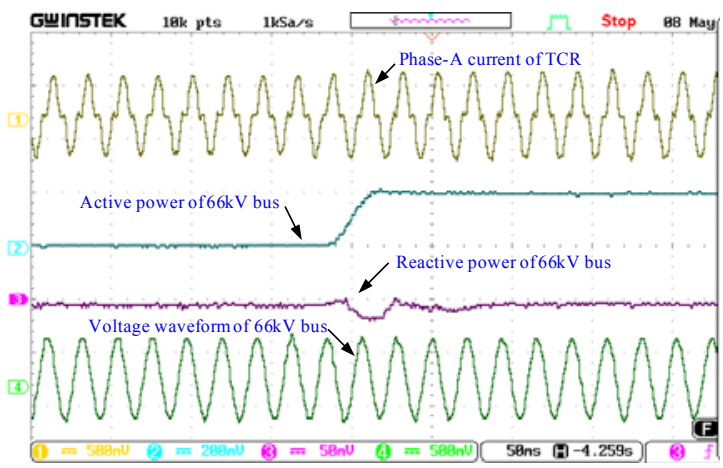

(a) Opal-RT results of PFC with SVC under step control signal and current source load (1:ITCR_ab; 2:P66; 3:Q66; 4:U66)

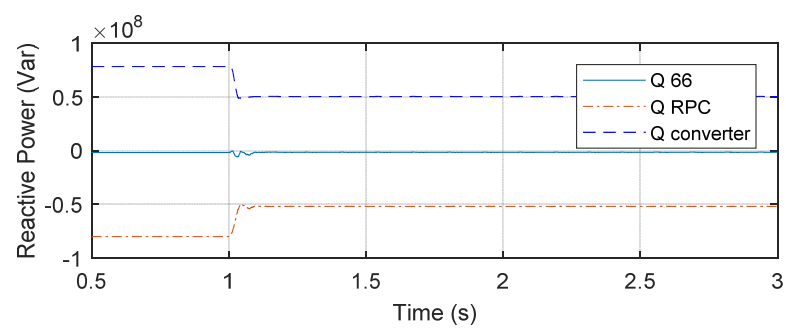

(b) Simulation results of reactive power regulation based on Matlab

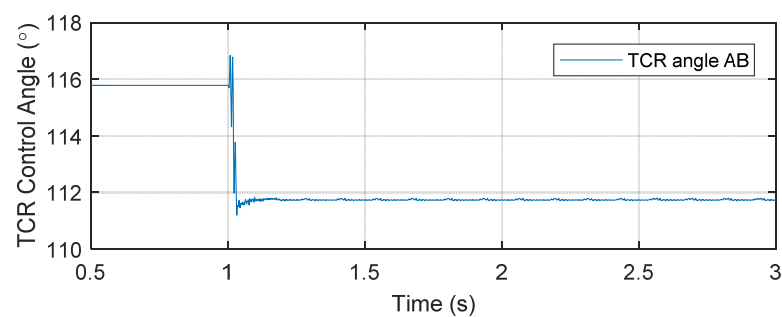

(c) Simulation result of TCR control angle based on Matlab

Figure 9 Results of reactive power compensation in distribution network system.

\section{STUDENT FEEDBACK}

The purpose of "learning evaluation" questionnaire is to get feedback from students about exercise evaluation and students' opinions on related matters. Questionnaire responses to the following four teaching objectives:

(1) Cognitive simulation is an experimental method for the study of complex electrical system, which can understand the model types, basic elements and simulation tools;

(2) Master the basic theory and method of electrical complex system modelling, and understand the model validation;

(3) Master the system design and analysis based on system modelling and simulation experiment, deeply understand the learned knowledge and expand the scope of knowledge;

(4) Understand the application of advanced simulation technology (virtual prototype, physical / semi physical simulation) in electrical complex system modelling and design.

The above four aspects support the graduation requirements: for complex electrical engineering problems, graduates are able to use appropriate simulation tools or development platform for simulation analysis and design.

Students were asked to provide 5-level selfevaluation on the four teaching objectives $(1: 1.0-0.9 ; 2$ : $0.89-0.80 ; 3: 0.79-0.70 ; 4: 0.69-0.60 ; 5:<0.60)$. As for the improvement suggestions and general comments, there are also two open questions: (1) Please evaluate the teachers' teaching; (2) please give your own opinions and suggestions on the course. This course is a professional elective course. The "learning evaluation" questionnaire of 45 students was collected. Figure10 shows the students' questions and feedback.

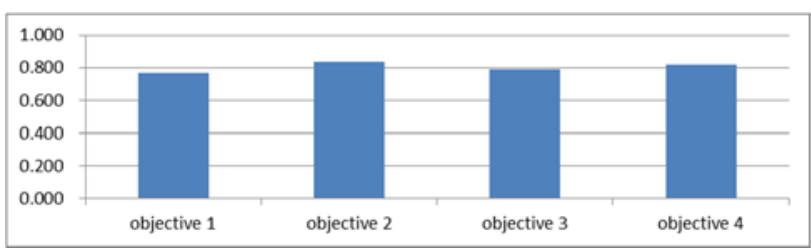

Figure 10 Statistical results of "learning evaluation" questionnaire.

As can be seen from Figure 10, although the students are short of time in the fourth grade, they are very interested in learning course "comprehensive analysis of electrical system" based on HIL simulation platform, and they can master the content better. At the same time, the theoretical knowledge of the course needs to be improved (the self-evaluation achievement of objective 1 is 0.767 ). 
Another gratifying phenomenon is that students are eager to verify the algorithm based on HIL simulation platform in their graduation thesis. Since 2018, about 12 undergraduates have chosen topics related to real-time simulation on HIL simulation platform. The main topics include: stability and accuracy of HIL simulation, voltage rise suppression of distributed PV grid connection, control of hybrid off grid system, development and test of PV inverter control, coordinated voltage control of distribution network, demand response and verification of electric vehicle driving strategy.

A questionnaire was distributed to 8 graduates. The contents are as follows: (1) real time simulation is a useful tool for graduation thesis; (2) In thesis, it is more interesting or useful to use hardware devices than simple simulation. The graduates surveyed highly praised the use of real-time simulation. They believe that this has a profound impact on their learning experience, and affirm the similarities between HIL simulation experiment and real objects, as well as the novelty of this method. Moreover, compared with pure simulation, graduates find the hardware experience much more interesting and inspiring.

\section{CONCLUSION}

The hardware experiment and software simulation experiment are combined in the semi-physical simulation. It can help students understand the hardware equipment in the practical application, and keep the flexibility and modeling ability of digital simulation. In this paper, based on HIL simulation platform for scientific research, four experimental projects, including inrush current characteristics of three-phase transformer, electromagnetic transient experiment of power system, four-quadrant operation of converter and reactive power compensation characteristics of power quality, are designed for course "comprehensive analysis of electrical system". They cover the courses of electrical machinery, power electronics and power system. These experimental projects also reflect the system level interaction of professional knowledge.

The students made clear positive evaluation on the four experimental projects involved in the course, and affirmed the educational role of HIL real-time simulation for them. In addition, they are interested in integrating industrial equipment into experimental practice and getting practical operation on actual equipment.

\section{ACKNOWLEDGMENTS}

The authors gratefully acknowledge the support of teaching quality project of Anhui Province (2019jyxm0079). Moreover, the authors acknowledge the support of the agreement on academic and scientific cooperation between Anhui University and The ITER international fusion energy organization (ITER ref No 4300001754).

\section{REFERENCES}

[1] Certification standard for Engineering Education (revised in Nov. 2017). https://www.ceeaa. org.cn /gcjyzyrzxh/rzcxjbz/gcjyrzbz/tybz/index.html

[2] D. Celeita, M. Hernandez, G. Ramos, N. Penafiel, M. Rangel and J.D. Bernal, Implementation of an educational real-time platform for relaying automation on smart grids, Elect. Power Syst. Res., vol. 130, pp. 156-166, Jan. 2016. DOI: https://doi.org/10.1016/j.epsr.2015.09.003

[3] A.S. Deese, Development of smart electric power system (SEPS) laboratory for advanced research and undergraduate education, IEEE Trans. Power Syst., vol. 30, no. 3, pp. 1279-1287, May 2015. DOI:https://doi.org/10.1109/TPWRS.2014.234352

[4] RT-lab Technology. https://www.opal-rt.com

[5] T. Strasser, M. Stifter, et al, Co-simulation training platform for smart grids, IEEE Trans. Power Syst., vol. 29, no. 4, pp. 1989-1997, Jul. 2014.

DOI: https://doi.org/10.1109/TPWRS.2014.2305740

[6] G. Lauss, M.O. Faruque, et al., Characteristics and design of power hardware-in-the-loop simulations for electrical power systems, IEEE Trans. Ind. Electron., vol. 63, no. 1, pp. 406-417, Jan. 2016. DOI: https://doi.org/10.1109/TIE.2015.2464308

[7] S.N. Vukosavic, Electrical Machines[M], Springer, New York, 2013

[8] J.P. Kang, J. Wang, M.J. Liu and Y.L. Luo, Simulation of magnetizing inrush current in transformer based on the object orientated technique, Journal of EEE, vol. 30, no. 4, pp.50-53. (in Chinese)

[9] S. Savulescu, Real-Time Stability in Power Systems (Second edition) Springer, New York, 2014. DOI: https://doi.org/10.1007/978-3-31906680-6

[10] B.L. Dokic, B. Blanusa. Power Electronics Converters and Regulators (Third edition) Springer, New York, 2015. DOI: https://doi.org /10.1007 /978-3-319-09402-1

[11] Z.A. Wang, J.J Liu and Y. Wang, et al. Harmonic suppression and reactive power compensation (Third edition). China Machine Press, 2017 